\title{
Evaluation of Nutritional Knowledge in Terms of Dietary Sources of Protein, Phosphorous, Potassium and Fluids Restriction in Hemodialysis Patients
}

\author{
Rahele Sadat Montazeri ${ }^{1}$; Nasrin Sharifi ${ }^{2, *}$ \\ ${ }^{1}$ Student Research Committee, Ahvaz Jundishapur University of Medical Sciences, Ahvaz, IR Iran \\ ${ }^{2}$ Department of Nutrition, School of Paramedicine, Ahvaz Jundishapur University of Medical Sciences, Ahvaz, IR Iran \\ ${ }^{*}$ Corresponding author: Nasrin Sharifi, Department of Nutrition, School of Paramedicine, Ahvaz Jundishapur University of Medical Sciences, Ahvaz, IR Iran. Tel: +98-9133058234, Fax: \\ +98-6113738330, E-mail:n_sharifi_nutr@yahoo.com
}

Received: May 16, 2013; Revised: June 16, 2013; Accepted: July 28, 2013

\begin{abstract}
Background: There has not been any published literature in Iran about the evaluation of hemodialysis patients' knowledge in relation to dietary sources of protein, phosphorus, potassium, sodium and fluids.

Objectives: Therefore, the present study was performed with this aim, in patients with renal failure treated with hemodialysis.

Patients and Methods: Fifty hemodialysis patients were recruited. Demographic information, and anthropometric characteristics, were collected and measured. Awareness of nutrition in six parts (fluids, proteins, phosphorus, sodium, potassium, and cooking methods) was analyzed through a validated questionnaire.

Results: The mean age of the participants was $47.5 \pm 14.9$ years. In total, $26 \%$ of the patients had a poor knowledge of nutrition, $58 \%$ had a moderate understanding, and only $16 \%$ had good nutritional knowledge. In addition, the level of nutritional knowledge was significantly greater in patients with higher educational levels than those with primary education or lower. The mean score of knowledge about dietary sources of phosphorous and potassium was significantly lower than that of the other parts $(\mathrm{P}<0.001)$. Furthermore, nutritional awareness regarding dietary sources of protein did not significantly differ from fluids restriction; however, it was significantly lower than sodium and cooking methods $(\mathrm{P}<0.001)$ and significantly higher than phosphorus and potassium $(\mathrm{P}<0.01)$.

Conclusions: Patients' knowledge scores about dietary sources of phosphorous and potassium were significantly lower than those of other parts. It is worth noting that qualified doctors, nurses and dieticians, should educate hemodialysis patients in relation to their literacy levels, especially when describing dietary sources of phosphorus, potassium and protein.
\end{abstract}

Keywords:Nutrition Science; Hemodialysis; Phosphorous; Potassium

\section{Background}

Chronic kidney disease (CKD) is one of the major public health problems, worldwide (1). The number of patients with CKD is increasing parallel to the increase in hypertension and the prevalence of diabetes (2). Current medical treatment methods for end stage renal disease (ESRD) include; hemodialysis, peritoneal dialysis and kidney transplantation (3). However, the most common renal replacement therapy is hemodialysis (HD) (3). In Iran, based on the results of a study with a large population in Tehran, the reported prevalence of CKD was 18.9\% in the year 2009 (4). Furthermore, the rate of ESRD has increased from 238 cases in 2000 to 357 cases per one million of population in 2006 (5). Renal diet adherence and fluid restriction play an important role in the care and health maintenance of hemodialysis patients. Lack of sufficient protein and energy intake in hemodialysis patients, who lose amino acids through dialysis, causes protein-energy malnutrition and increases mortality rates $(6,7)$. A high intake of sodium, potassium and phosphorous from an inappropriate diet may lead to; lung edema, congestive heart failure, arrhythmia, bone disease and premature death $(8,9)$. According to the important role of the renal diet in the prevention of the ESRD complications, a question that arises is to what extent are renal patients aware of these dietary recommendations. There is a lack of studies evaluating this issue in Iran. Only one published study has assessed nutritional knowledge, attitude and performance of hemodialysis patients in Tabriz, Northwest Iran (10). The results of this study showed that more than half of the hemodialysis patients had a lower than average nutritional knowledge. However, this study did not clearly explain the method of knowledge assessment and questionnaire designation (10). On the other hand, how much do hemodialysis patients know about the adequate protein intake, fluid and electrolyte restriction separately, is also important.

\section{Objectives}

Therefore, the present study was performed to evaluate the knowledge of hemodialysis patients in terms of the need for dietary protein, electrolyte and fluid restriction. 


\section{Patients and Methods}

In this descriptive-analytical study, 50 patients attending the hemodialysis sector of Golestan Hospital in the Ahvaz Jundishapur University of Medical Sciences were recruited using a simple random sampling procedure in 2012. Considering the appropriate nutritional knowledge and attitude's rates among HD patients in the Alipour et al. study which were $1.4 \%$ to $2.8 \%$, we calculated our study sample size to be 45 at a $95 \%$ confidence level, and a margin of error equal to 0.05 .

After the patient had signed a consent form, demographic information including; age, gender, education, duration of hemodialysis treatment and medical history were collected. Height was measured without shoes using a stadiometer with a precision of $0.1 \mathrm{~cm}$. Weight was measured in light clothes to the nearest $0.1 \mathrm{~kg}$. Body Mass Index (BMI) was calculated as weight ( $\mathrm{kg}$ ) divided by height squared $\left(\mathrm{m}^{2}\right)$.

The patients' level of nutritional knowledge was evaluated by a questionnaire called the 'Nutritional Knowledge Assessment Questionnaire for Hemodialysis (NKAQH) which was designed and validated as follows. Questions of the NKAQH were designed according to nutritional guidelines provided by scientific authorities for renal diseases $(11,12)$. We also endeavored to include fluent and understandable questions for the patients. The questionnaire consisted of 23 multiple-choice questions that assessed the patients' nutritional knowledge in six parts including; fluid intake (4 questions), protein (4 questions), potassium (6 questions), sodium (2 questions), phosphorous (5 questions) and cooking methods (2 questions). The NKAQH was submitted to a nephrologist and two nutritionists to determine its content validity. Then, revisions were made based on their comments. The reliability of the questionnaire was measured using a Cronbach's alpha which was calculated to be 0.84 . We used the total score of the NKAQH, and scores for each part, to analyze the results of the study. Considering one point for every correct answer, the range of the NKAQH's total scores was 0 to 23 . We divided it into three categories: 1 -Poor knowledge $=$ total score less than 8, 2-Average knowledge $=$ total score between 8 and 16, and 3- Good knowledge $=$ total score greater than 16. Additionally, in order to assess the patient's nutritional knowledge in the six parts separately, we added the correct answers for each section and then divided this score into the total number of questions in each part. Then the calculated number was multiplied by 10 to obtain an equal scale for comparing the mean scores between the separate sections.

Descriptive statistics were used to show the mean, standard deviation and frequency of the data. We used an independent t-test and one way ANOVA to compare the means of the data between two independent and several independent groups, respectively. A Pearson's correlation coefficient was calculated to assess the correlation be- tween variables. Analysis was conducted, using SPSS version 17 statistical software (SPSS Inc, Chicago, Ill). P-values $<0.05$ were considered statistically significant. The study protocol was approved by the Ahvaz Jundishapur University of Medical Sciences' Ethics Committee.

\section{Results}

The mean age of our study subjects ( 50 hemodialysis patients: 23 men and 27 women) was $47.5 \pm 14$.89years (range: 19 to 72 years). Demographic and anthropometric data are shown in Table 1 . The mean total score of patients' nutritional knowledge was $10.38 \pm 4.69$. In total, $26 \%$ of subjects had a poor knowledge of nutrition, $58 \%$ had average and only $16 \%$ had a good level of knowledge (Figure 1). Overall, the patients' who had a high school education or university degree had NKAQH scores which were significantly higher than those of patients who had a primary education or lower $(14.3 \pm 3.95$ vs. $9.7 \pm 4.23$, respectively, $\mathrm{P}=0.005)$. A significant correlation was not seen between the total NKAQH score and the duration of hemodialysis $(r=0.18, P=0.20)$, age of patients $(r=-0.18$, $\mathrm{P}=0.19)$ and BMI $(\mathrm{r}=-0.06, \mathrm{P}=0.65)$. Furthermore, the mean score of the NKAQH was not significantly different between men and women (10.47 \pm 4.03 vs. $10.29 \pm 5.26$, respectively, $\mathrm{P}=0.89$ ).

Table 1. Educational Levels, Anthropometric Characteristics and History of Underlying Disease in Hemodialysis Patients $(\mathrm{n}=50)^{\mathrm{a}, \mathrm{b}}$

\begin{tabular}{|c|c|}
\hline Variables & Results \\
\hline \multicolumn{2}{|l|}{ Educational level } \\
\hline Illiterate & 18 \\
\hline Primary school & 44 \\
\hline Guidance school & 4 \\
\hline Diploma & 24 \\
\hline Upper levels & 10 \\
\hline Weight, kg & $66.46 \pm 15.5$ \\
\hline BMI, $\mathrm{kg} / \mathrm{m}^{2}$ & $23.51 \pm 5.05$ \\
\hline \multicolumn{2}{|l|}{ BMI categories } \\
\hline$\leq 18.49, \mathrm{~kg} / \mathrm{m}^{2}$ & 18 \\
\hline $18.5-24.99, \mathrm{~kg} / \mathrm{m}^{2}$ & 44 \\
\hline $25-29.99, \mathrm{~kg} / \mathrm{m}^{2}$ & 28 \\
\hline$\geq 30, \mathrm{~kg} / \mathrm{m}^{2}$ & 10 \\
\hline Duration of hemodialysis treatment, months & $25.05 \pm 28.64$ \\
\hline \multicolumn{2}{|l|}{ Underlying disease } \\
\hline Hypertension & 42 \\
\hline Diabetes and hypertension & 19 \\
\hline Hyperlipidemia, diabetes and hypertension & 13 \\
\hline Atherosclerosis and hypertension & 13 \\
\hline Hyperlipidemia and hypertension & 3 \\
\hline $\begin{array}{l}\text { Atherosclerosis, diabetes, hyperlipidemia and } \\
\text { hypertension }\end{array}$ & 10 \\
\hline
\end{tabular}




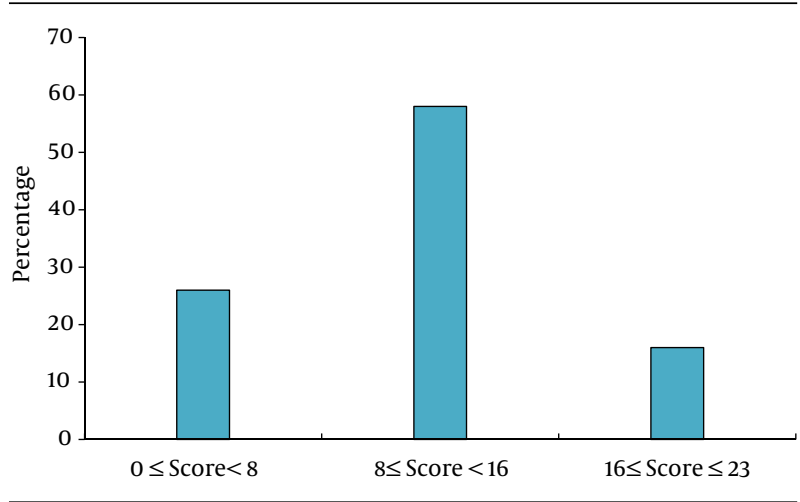

Figure 1. Classification of the Total Score of Hemodialysis Patients' Nutritional Knowledge Based on the Nutritional Knowledge Assessment Questionnaire for Hemodialysis (Range: 0-23)

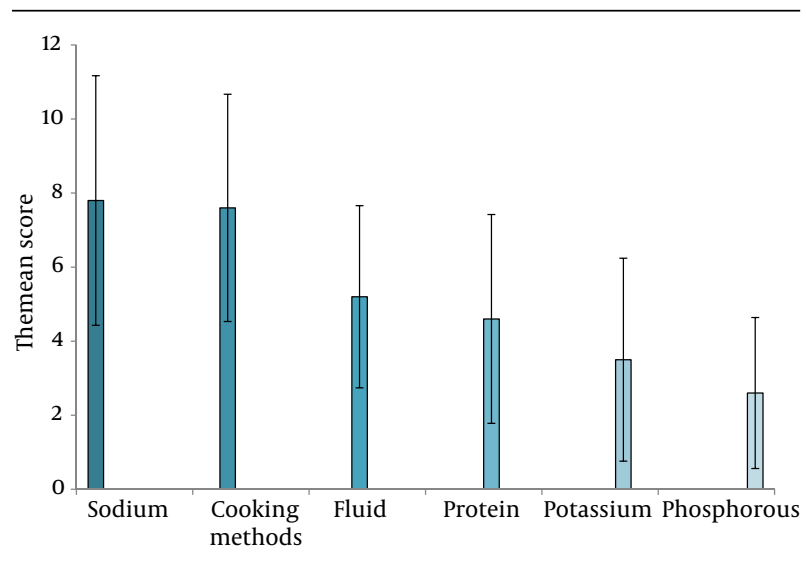

Figure 2. Mean Scores of Hemodialysis Patients' Knowledge Regarding Dietary Sources of Protein, Phosphorous, Potassium, Sodium, Fluid and Cooking Methods Based on the Nutritional Knowledge Assessment Questionnaire for Hemodialysis (Scores' range: 0-10)

The mean score for each part of the NKAQH in terms of; fluid intake, protein, sodium, potassium, phosphorous and cooking methods, are shown in Figure 2 (the range of scores was between 0 and 10). Nutritional knowledge about sodium intake and cooking methods was higher than in the other parts $(\mathrm{P}<0.001)$. Furthermore, nutritional awareness in relation to dietary sources of protein did not significantly differ from that of fluid restriction; however, it was significantly lower than sodium and cooking methods $(\mathrm{P}<0.001)$ and significantly higher than phosphorus and potassium $(\mathrm{P}<0.01)$. The mean score of knowledge about dietary sources of phosphorous and potassium was significantly lower than that of the other parts $(\mathrm{P}<0.001)$.

\section{Discussion}

The results of the present study showed that about $84 \%$ of hemodialysis patients had a poor or moderate knowledge of renal dietary recommendations. The patients who had a higher level of education also had a higher nutritional knowledge score than those who had a primary or lower level of education. This was consistent with the results of Alipour et al. study which reported that nutritional knowledge was low in $53 \%$ of renal patients (10). Moreover, they found a significant positive association between educational levels and nutritional knowledge scores (10). Also, similar to the study by Alipour et al. we did not find any significant correlation between the patients' nutritional knowledge and the duration of dialysis, age, BMI and gender.

The difference between the present study and previous ones performed in other countries, such as the study by Nerbass et al. in Brazil (13), is that the nutritional knowledge of their renal patients was higher than our participants. Patients in the Nerbass et al. study, who suffered from hyper phosphatemia, had a good knowledge of dietary sources of phosphorous, although their adherence to the diet was poor (13). However in our study, the hemodialysis patients had not yet reached an appropriate level of nutritional knowledge, let alone be expected to have a good performance in terms of adherence to the renal diet. This reflects the fact that hemodialysis patients in our research had not received enough nutritional education to achieve optimal knowledge.

In the present study, the knowledge scores of hemodialysis patients regarding dietary sources of phosphorous and potassium were significantly lower than those of the other parts. Furthermore, our subjects had a moderate knowledge of fluid intake and dietary sources of protein. These findings indicate that it is necessary to improve the nutritional knowledge of hemodialysis patients about dietary sources of phosphorous and potassium. Our results were similar to the Pollock and Jaffery study who designed a questionnaire named the Chronic Kidney Disease Knowledge Assessment Tool for Nutrition (CKDKAT$\mathrm{N})$ to compare nutritional knowledge of phosphorous with that of other dietary components in hemodialysis patients (14). Their findings showed that the knowledge of hemodialysis patients about dietary sources of phosphorous was significantly lower than that of potassium, sodium and protein (14). In addition, Cupisti et al. compared the knowledge of hemodialysis patients with that of the nurses who worked in the dialysis section using the CKDKAT-N (15). The knowledge scores of the hemodialysis patients were significantly lower than that of the nurses. Moreover, the patients' knowledge in regard to dietary sources of phosphorous was significantly lower than that of the other parts (15). Inadequate control on dietary intake of phosphorous leads to adverse effects in hemodialysis patients, such as cardiovascular disorders, hyperparathyroidism and osteodystrophy $(16,17)$. Therefore, appropriate education of hemodialysis patients to control their dietary phosphorous intake is one of the most important tasks of the medical team, including nephrologists, nurses and dieticians.

In our study the nutritional knowledge of hemodialysis patients about dietary sources of potassium was also poor. Unlike our results, the awareness of hemodialysis 
patients about dietary potassium was significantly higher than that of phosphorous in the Pollock and Jaffery study (14). Fluctuations in serum potassium may lead to cardiac arrhythmia and that is dangerous for hemodialysis patients (18). Thus, education of patients and their families concerning dietary sources of potassium in the case of hyper- or hypokalemia may be particularly helpful.

The knowledge scores of protein and fluid intake were only moderate in our subjects. Hemodialysis patients lose a significant amount of protein through dialysis, therefore, they should consume enough daily dietary sources of high biological value protein that produce a low amount of urea, such as poultry or fish as well as egg whites. This recommendation prevents protein-energy malnutrition and decreases mortality rates in hemodialysis patients (7). Fluid accumulation in the body of ESRD patients between two sessions of hemodialysis could increase mortality rates due to cardiovascular disorders (19, 20). Consequently, education on ways to control thirst and lower the intake of both sodium and fluid is one important nutritional strategies in hemodialysis patients.

One of the limitations of this study was the lack of a validated questionnaire in the Persian language to assess the nutritional knowledge of hemodialysis patients, especially for the different components of a renal diet such as; protein, electrolyte and fluid intake. Therefore we tried to design a questionnaire with these aims and to evaluate its validity and reliability. The validity of the questionnaire was verified by nutritionists and nephrologists and the internal reliability was confirmed using a Cronbach's alpha. Thus, we recommend the use of the NKAQH questionnaire to other researchers and therapists.

In conclusion, about $84 \%$ of hemodialysis patients in the present study had a poor or moderate knowledge of nutrition. Furthermore, knowledge scores for dietary sources of phosphorous and potassium were significantly lower than those of the other dietary components. It seems that these patients had not received enough nutritional education to control hemodialysis complications. Thus, it is important that qualified doctors, nurses and dieticians, educate hemodialysis patients in relation to their literacy levels, especially about dietary sources of phosphorus, potassium and protein. For example, appropriate tables, images, films and pamphlets could be used to educate illiterate patients about dietary sources of potassium. It is also recommended that hospital staff, including doctors, nurses and dieticians, work together as a medical team to provide the necessary nutritional education to hemodialysis patients. In this regard, referring renal patients to dieticians by nephrologists can be very effective in controlling the disease's complications. Because nurses may have more communication with hemodialysis patients, it is also suggested that their nutritional knowledge is evaluated and if necessary retraining classes about renal diet should be held for them. Finally, the permanent presence of dieticians in hospital dialy- sis sections to provide education to improve patient's knowledge of nutrition is also necessary.

\section{Acknowledgements}

This study would not have been possible without the help and participation of the patients.

\section{Authors' Contributions}

N. Sharifi: designed the research study, supervised the research and wrote the manuscript; RS Montazeri: designed the research study, performed the research and collected the data.

\section{Financial Disclosure}

The authors declare that they have no conflict of interest.

\section{Funding/Support}

This work was financially supported by the Student Research Committee of Ahvaz Jundishapur University of Medical Sciences (Grant Number: 91 S.43).

\section{References}

1. Collins AJ, Foley RN, Chavers B, Gilbertson D, Herzog C, Johansen K, et al. 'United States Renal Data System 2011 Annual Data Report: Atlas of chronic kidney disease \& end-stage renal disease in the United States. Am J Kidney Dis. 2012;59(1 Suppl 1).

2. Coresh J, Selvin E, Stevens LA, Manzi J, Kusek JW, Eggers P, et al. Prevalence of chronic kidney disease in the United States. JAMA. 2007;298(17):2038-47.

3. National Kidney and Urologic Diseases Information Clearinghouse.. Treatment Methods for Kidney Failure: Hemodialysis.: National Institutes of Health; 2011. Available from: http://kidney. niddk.nih.gov/kudiseases/pubs/hemodialysis/.

4. Hosseinpanah F, Kasraei F, Nassiri AA, Azizi F. High prevalence of chronic kidney disease in Iran: a large population-based study. BMC Public Health. 2009;9:44.

5. Aghighi M, Heidary Rouchi A, Zamyadi M, Mahdavi-Mazdeh M, Rajolani H, Ahrabi S, et al. Dialysis in Iran. Iran J Kidney Dis. 2008;2(1):11-5.

6. Kalantar Zadeh K, Ikizler TA, Block G, Avram MM, Kopple JD. Malnutrition-inflammation complex syndrome in dialysis patients: causes and consequences. Am J Kidney Dis. 2003;42(5):864-81.

7. Kovesdy CP, Shinaberger CS, Kalantar-Zadeh K. Epidemiology of dietary nutrient intake in ESRD. Semin Dial. 2010;23(4):353-8.

8. Esposito C, Bellotti N, Fasoli G, Foschi A, Plati AR, Dal Canton A Hyperkalemia-induced ECG abnormalities in patients with reduced renal function. Clin Nephrol. 2004;62(6):465-8.

9. Pasticci F, Fantuzzi AL, Pegoraro M, McCann M, Bedogni G. Nutritional management of stage 5 chronic kidney disease.J Ren Care. 2012;38(1):50-8.

10. Alipour B, Koushavar H, Alipour Ajiri S, Alipourfard A, Karimnejad M. [Study of knowledge, attitude and practice of renal patients undergoing hemodialysis]. J Tabriz Univ Med Sci. 2003;56:57-62.

11. National Kidney Foundation . Clinical practice guidelines for nutrition in chronic renal failure. Am J Kidney Dis. 2003;35:S1-140.

12. National Kidney and Urologic Diseases Information Clearing house . Kidney Failure: Eat Right to Feel Right on Hemodialysis.: National Institutes of Health; 2012. Available from: http://kidney. niddk.nih.gov/KUDiseases/pubs/eatright/index.aspx.

13. Nerbass FB, Morais JG, dos Santos RG, Kruger TS, Koene TT, da Luz Filho HA. Adherence and knowledge about hyperphosphatemia treatment in hemodialysis patients with hyperphosphatemia. $J$ Bras Nefrol. 2010;32(2):149-55. 


\section{Montazeri RS et al.}

14. Pollock JB, Jaffery JB. Knowledge of phosphorus compared with other nutrients in maintenance dialysis patients. $J$ Ren Nutr. 2007;17(5):323-8.

15. Cupisti A, Ferretti V, D'Alessandro C, Petrone I, Di Giorgio A, Meola $\mathrm{M}$, et al. Nutritional knowledge in hemodialysis patients and nurses: focus on phosphorus. J Ren Nutr. 2012;22(6):541-6.

16. Nishizawa Y, Jono S, Ishimura E, Shioi A. Hyperphosphatemia and vascular calcification in end-stage renal disease. J Ren Nutr. 2005;15(1):178-82.

17. Noori N, Kalantar-Zadeh K, Kovesdy CP, Bross R, Benner D, Kopple JD. Association of dietary phosphorus intake and phosphorus to protein ratio with mortality in hemodialysis patients. Clin J Am Soc Nephrol. 2010;5(4):683-92.
18. Checherita IA, David C, Diaconu V, Ciocalteu A, Lascar I. Potassium level changes--arrhythmia contributing factor in chronic kidney disease patients. Rom J Morphol Embryol. 2011;52(3 Suppl):1047-50.

19. Kalantar-Zadeh K, Regidor DL, Kovesdy CP, Van Wyck D, Bunnapradist S, Horwich TB, et al. Fluid retention is associated with cardiovascular mortality in patients undergoing long-term hemodialysis. Circulation. 2009;119(5):671-9.

20. Lindley EJ. Reducing sodium intake in hemodialysis patients. Semin Dial. 2009;22(3):260-3. 